\title{
Synthesis of a Symmetric Cylindrical Bis(crown ether) Host and Its Complexation with Paraquat
}

Feihe Huang, ${ }^{\vee}$ Lev N. Zakharov, ${ }^{\ddagger}$ Arnold L. Rheingold, ${ }^{\ddagger}$ Mehdi Ashraf-Khorassani, ${ }^{\curlyvee}$ and Harry W. Gibson*,

${ }^{\checkmark}$ Department of Chemistry, Virginia Polytechnic Institute and State University, Blacksburg, Virginia 24061-0212, and

${ }^{\ddagger}$ Department of Chemistry and Biochemistry, University of California, San Diego, La Jolla, CA, 92093-0358

Supplemental Material (4 pages)

\section{Proton NMR spectrum of $\mathbf{3 b}$}
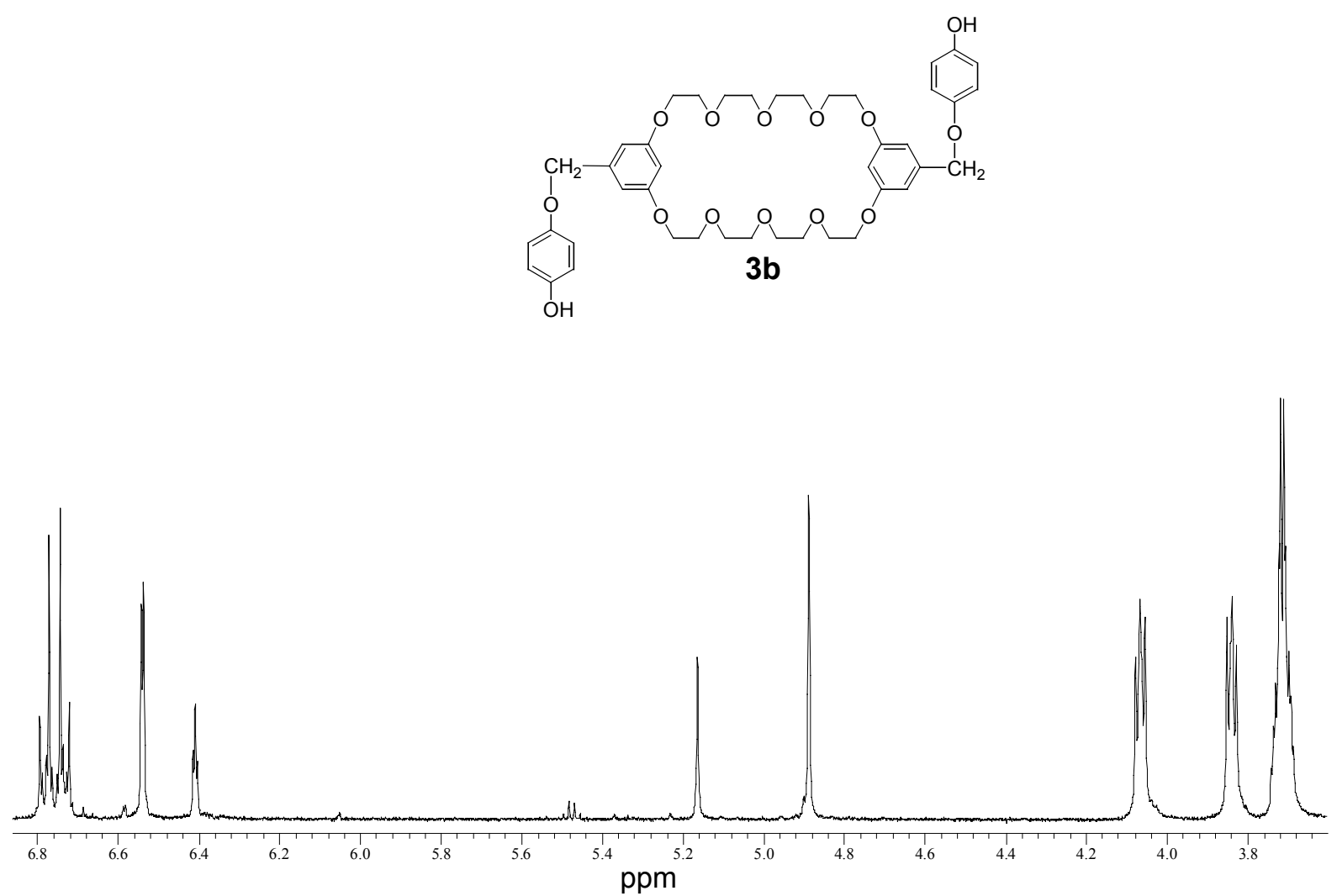

Figure S1. ${ }^{1} \mathrm{H}$ NMR Spectrum $\left(400 \mathrm{MHz}, \mathrm{CDCl}_{3}, 22{ }^{\circ} \mathrm{C}\right)$ of $\mathbf{3 b}$. 


\section{Proton NMR spectrum of 1}

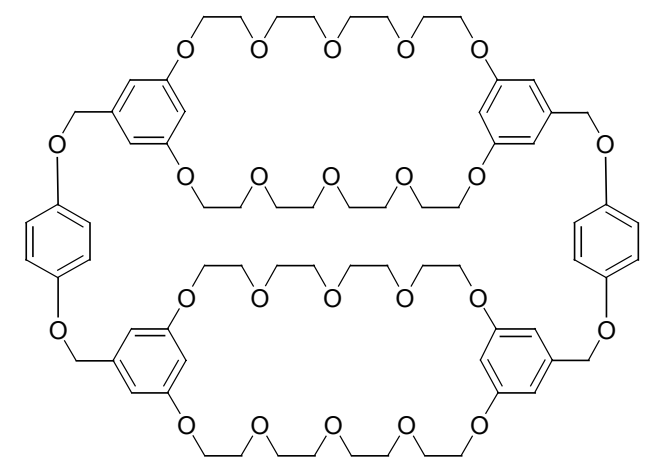

1

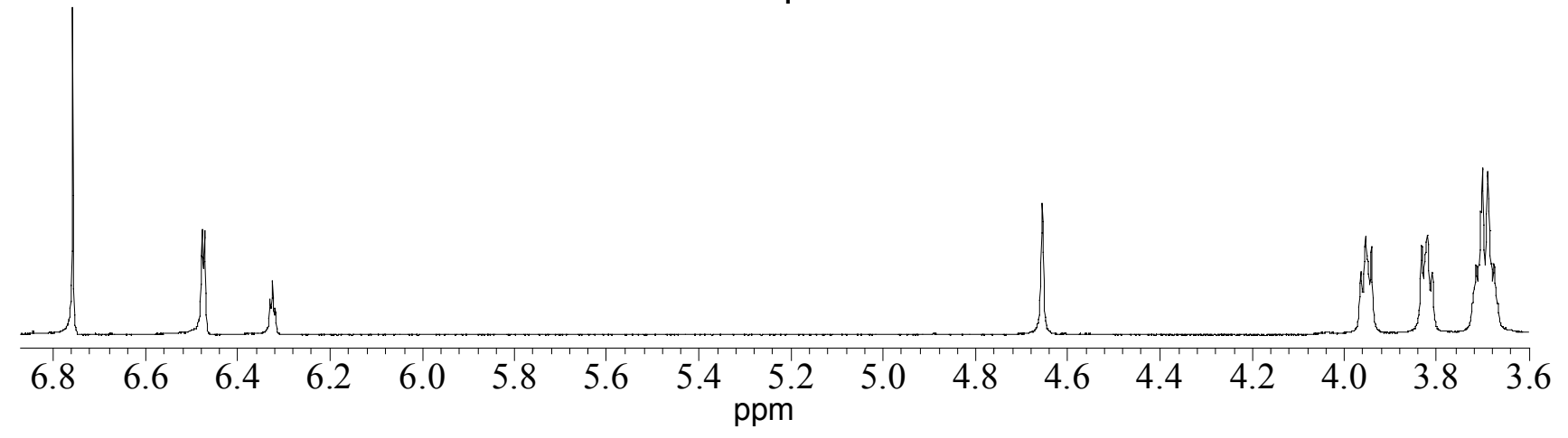

Figure S2. ${ }^{1} \mathrm{H}$ NMR Spectrum $\left(400 \mathrm{MHz}, \mathrm{CDCl}_{3}, 22^{\circ} \mathrm{C}\right)$ of $\mathbf{1}$.

3. ORTEP diagram of the X-ray crystal structure of 1

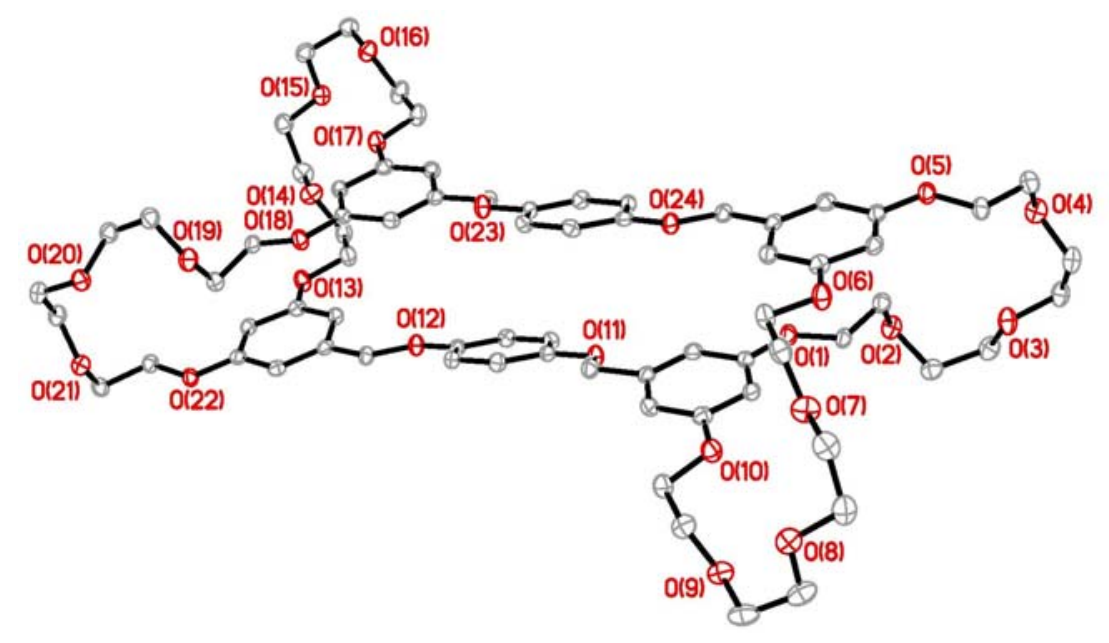


4. ORTEP diagrams of the X-ray crystal structure of $\mathbf{1 \cdot \mathbf { 2 } _ { 2 }}$
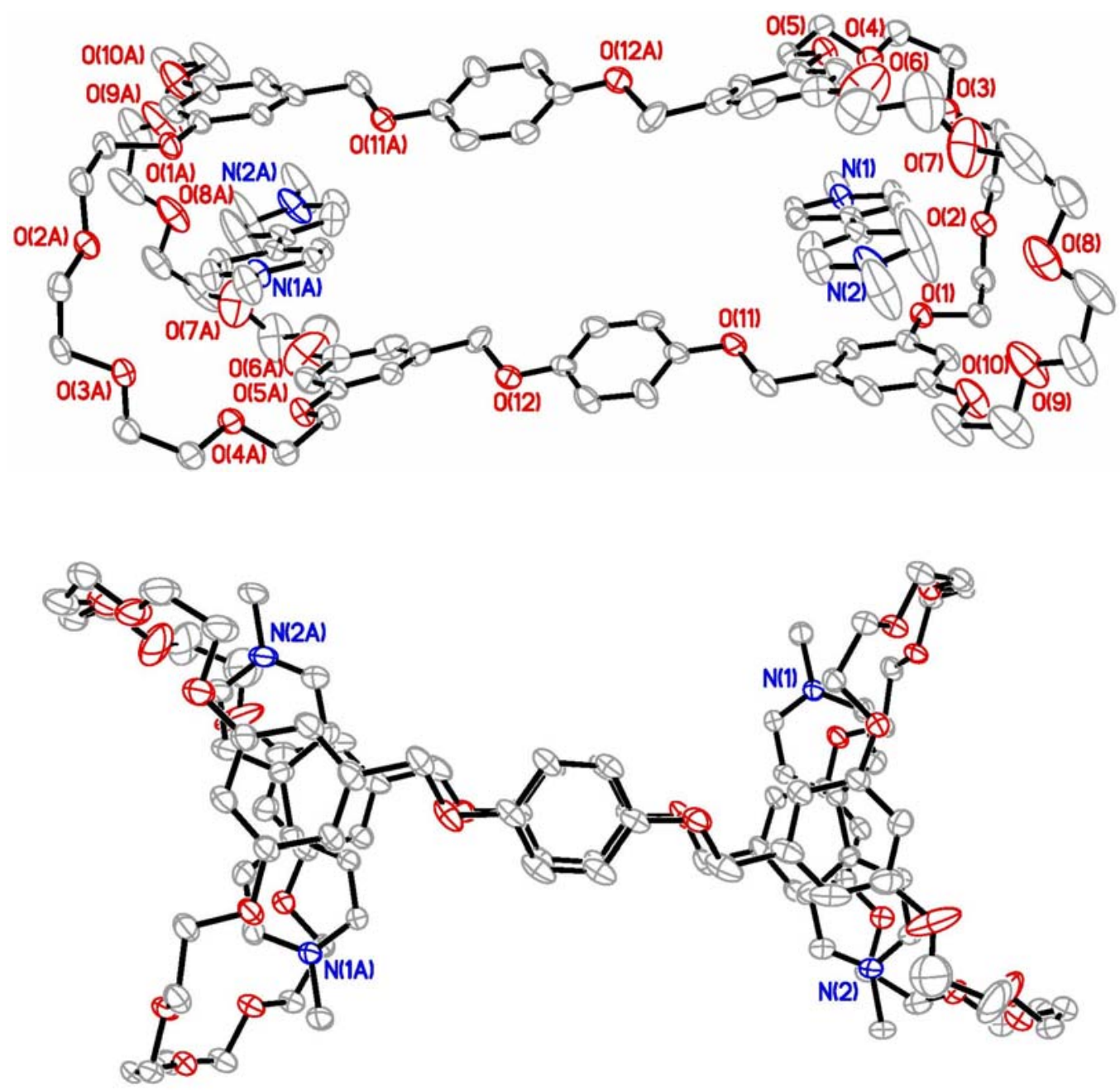
5. Determination of $\Delta_{0}$ of $\mathrm{H}_{1}$ for complexation between 1 and 2 in 5:1 acetone- $d_{6}$ :chloroform-d and acetone- $d_{6}$
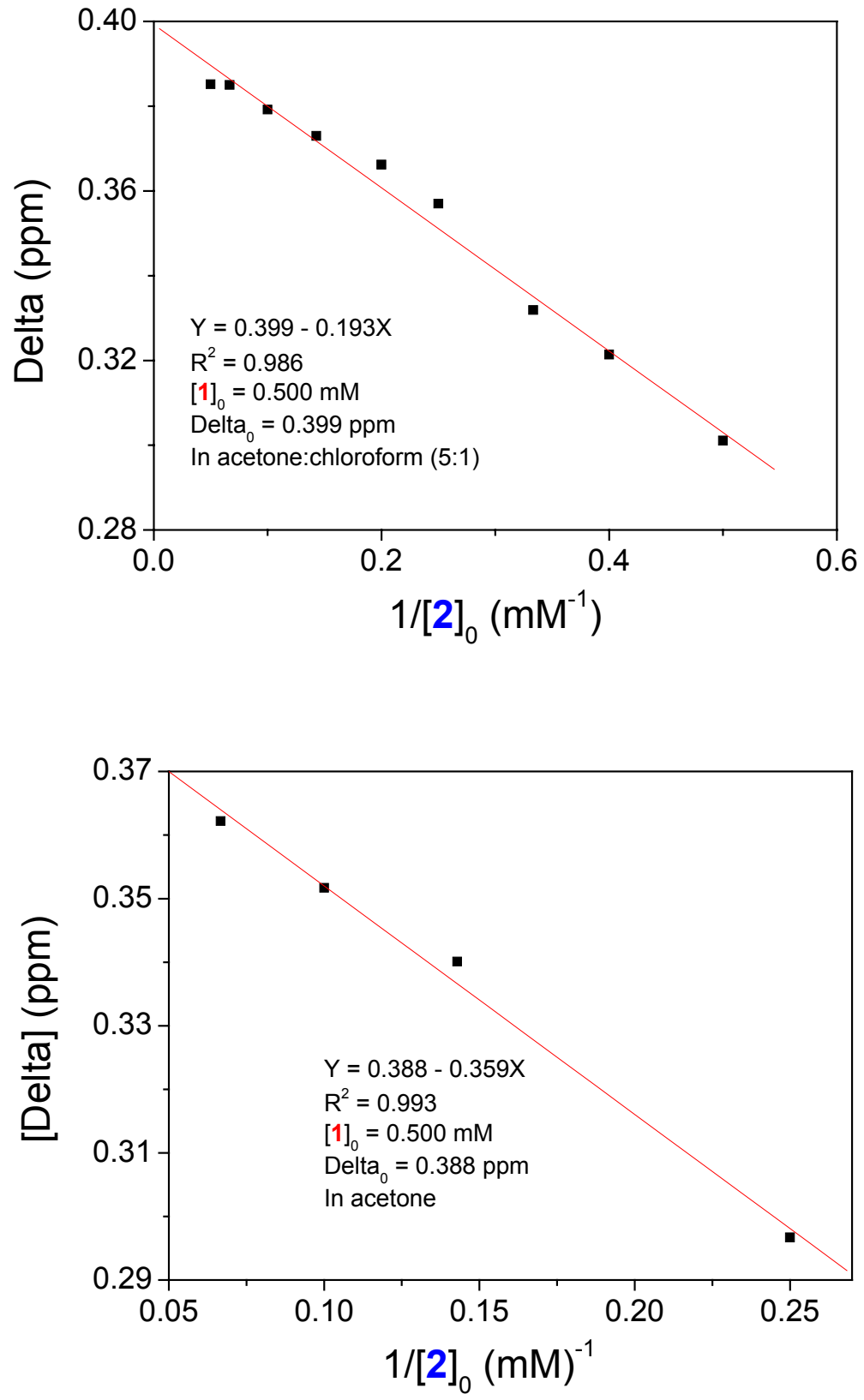